
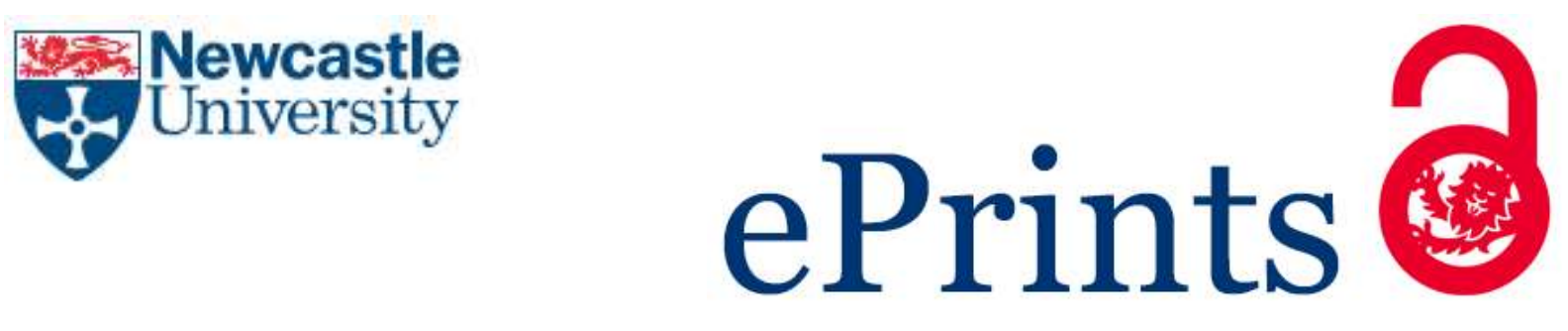

Dold P, Pandorf T, Flohr M, Preuss R, Bone MC, Joyce TJ, Holland J, Deehan D.

Acetabular shell deformation as a function of shell stiffness and bone strength. Proceeding of the Institute of Mechanical Engineers Part H: Journal of Engineering in Medicine 2016, 1-6.

Copyright:

The final publication is available from Sage Publications via

http://dx.doi.org/10.1177/0954411916632792

Date deposited:

$11 / 05 / 2016$

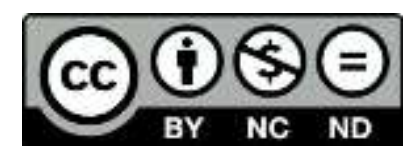

This work is licensed under a

Creative Commons Attribution-NonCommercial-NoDerivatives 4.0 International licence 


\section{Acetabular shell deformation as a function of shell stiffness and bone strength}

\begin{tabular}{|c|c|}
\hline Journal: & Part H: Journal of Engineering in Medicine \\
\hline Manuscript ID: & Draft \\
\hline Manuscript Type: & Original article \\
\hline Date Submitted by the Author: & $n / a$ \\
\hline Complete List of Authors: & $\begin{array}{l}\text { Dold, Philipp; Ceramtec GmbH, Medical Products Division } \\
\text { Pandorf, Thomas; Ceramtec GmbH, Medical Products Division } \\
\text { Flohr, Markus; Ceramtec GmbH, Medical Products Division } \\
\text { Preuss, Roman; Ceramtec GmbH, Medical Products Division } \\
\text { Bone, Martin; Newcastle University, School of Mechanical Engineering } \\
\text { Joyce, Tom; Newcastle University, School of Mechanical Engineering } \\
\text { Holland, James; Freeman Hospital, Newcastle Surgical Training Centre } \\
\text { Deehan, David; Freeman Hospital, Newcastle Surgical Training Centre }\end{array}$ \\
\hline Keywords: & $\begin{array}{l}\text { Biomechanical Testing/ Analysis, Hip Protheses, Combined stiffness, } \\
\text { Acetabular shell deformation, Acetabular shell stiffness }\end{array}$ \\
\hline Abstract: & $\begin{array}{l}\text { Press-fit acetabular shells used for hip replacement rely upon an } \\
\text { interference fit with the bone to provide initial stability. This process may } \\
\text { result in deformation of the shell. This study aimed to model shell } \\
\text { deformation as a process of shell stiffness and bone strength. } \\
\text { A cohort of } 32 \text { shells with two different wall thicknesses ( } 3 \text { and } 4 \mathrm{~mm} \text { ) and } \\
\text { ten different shell sizes ( } 44 \text { to } 62 \mathrm{~mm} \text { outer diameter) were implanted into } \\
8 \text { cadavers. Shell deformation was then measured in the cadavers using a } \\
\text { previously validated ATOS Triple Scan III optical system. The shell bone } \\
\text { interface was then considered as a spring system according to Hooke's law } \\
\text { and from this the force exerted on the shell by the bone was calculated } \\
\text { using a combined stiffness consisting of the measured shell stiffness and a } \\
\text { calculated bone stiffness. } \\
\text { The median radial stiffness the } 3 \mathrm{~mm} \text { wall thickness was } 4192 \mathrm{~N} / \mathrm{mm} \\
\text { (range } 2920 \text { to } 6257 \mathrm{~N} / \mathrm{mm} \text { ), whilst for the } 4 \mathrm{~mm} \text { wall thickness the } \\
\text { median was } 9633 \mathrm{~N} / \mathrm{mm} \text { (range } 6875 \text { to } 14341 \mathrm{~N} / \mathrm{mm} \text { ) } \\
\text { The median deformation was } 48 \mu \mathrm{m} \text { (range } 3 \text { to } 187 \mu \mathrm{m} \text { ), whilst the } \\
\text { median force was } 256 \mathrm{~N} \text { (range } 26 \mathrm{~N} \text { to } 916 \mathrm{~N} \text { ). No statistically significant } \\
\text { correlation was found between shell stiffness and deformation. Deformation } \\
\text { was also found to not be fully symmetric (centres } 180^{\circ} \text { apart), with a } \\
\text { median angle discrepancy of } 11.5^{\circ} \text { between the two maximum positive } \\
\text { points of deformation. Further work is still required to understand how the } \\
\text { bone influences acetabular shell deformation. }\end{array}$ \\
\hline
\end{tabular}

\section{SCHOLARONE \\ Manuscripts}


1

2

3

4

5

6

7

8

9

10

11

12

13

14

15

16

17

18

19

20

21

22

23

24

25

26

27

28

29

30

31

32

33

34

35

36

37

38

39

40

41

42

43

44

45

46

47

48

49

50

51

52

53

54

55

56

57

58

59

60

Philipp Dold ${ }^{1}$, Thomas Pandorf ${ }^{1}$, Markus Flohr ${ }^{1}$, Roman Preuss ${ }^{1}$, Martin C Bone ${ }^{2}$, Tom J Joyce ${ }^{2}$, James Holland ${ }^{3}$, David Deehan ${ }^{3}$

1 Ceramtec GmbH, Medical Products Division, Plochingen, Germany

2 Newcastle University, School of Mechanical Engineering, Newcastle upon Tyne, United Kingdom

3 Freeman Hospital, Newcastle Surgical Training Centre, Newcastle upon Tyne, United Kingdom

Correspondence to:

Philipp Dold

CeramTec GmbH

Medical Products Division

CeramTec-Platz 1-9

73207 Plochingen

Germany

Email: p.dold@ceramtec.de

\section{Keywords}

Biomechanical testing/ analysis, hip protheses, acetabular shell deformation, acetabular shell stiffness, combined stiffness

http://mc.manuscriptcentral.com/(site) 


\section{Introduction}

Press fit shells have increased in popularity over the past decade ${ }^{1}$. However it has been reported that deformation of the acetabular shell may disrupt the assembly process for modular shells. Additionally acetabular shell deformation has been linked to several individual variables such as diameter ${ }^{2}$ and wall thickness ${ }^{23}$. The authors have previously performed several studies examining acetabular shell deformation in cadavers ${ }^{567}$. In these experiments the ATOS Triple Scan III (ATOS) optical measurement system was trialled, validated and then utilised. A validation study determined that the maximum error of the ATOS was $5 \mu \mathrm{m}$ compared to a coordinate measuring machine (CMM) for measuring deformation at the shell rim $^{6}$.

The aim of this study was to examine how shell stiffness and bone strength influence the size of the deformation in a cadaveric model. The hypothesis was that higher shell stiffness values would result in lower deformation values as the shell would have greater resistance to loading. In addition the asymmetry of the deformation was investigated, to determine if the two maximum points of deformation were $180^{\circ}$ opposite one another and if they were the same magnitude. The hypothesis was that there would be some angular discrepancy and that the forces would not be the same size due to the structure of the acetabulum.

\section{Methods}

A cohort of shells was implanted into cadavers and the deformation measured. From this data the force exerted by the bone on the shell was then calculated by approximating the system using Hooke's law.

\section{Acetabular shells}

For these experiments custom made titanium alloy (TiAl6V4) shells of a generic design were used. A hole was threaded into the pole of the shell to enable insertion into cadavers via an impactor. Shell sizes between 44 and $64 \mathrm{~mm}$ were available in increments of two millimetres, with two different uniform wall thicknesses $3 \mathrm{~mm}$ and $4 \mathrm{~mm}$. The amount of under-reaming was altered for each shell between zero and $1 \mathrm{~mm}$.

Shell stiffness

In-vitro displacement measurements were performed to determine the radial stiffness of the shell. A uniaxial/ two point loading frame was used to compress the shells. This loading frame design has been described elsewhere ${ }^{8}$ and was previously utilised in validation tests performed by the authors ${ }^{6}$. Three different shell sizes (44, 54 and $64 \mathrm{~mm}$ outer diameter) and two wall thicknesses ( 3 and $4 \mathrm{~mm}$ ) were used for the verification. The load applied by the frame ranged between 0 and $2000 \mathrm{~N}(0 \mathrm{~N}, 100 \mathrm{~N}$, $200 \mathrm{~N}, 300 \mathrm{~N}, 500 \mathrm{~N}, 1000 \mathrm{~N}, 1500 \mathrm{~N}, 2000 \mathrm{~N}$ ).

The change in diameter was measured using a Mahr Vision MS 662 CMM (Mahr GmbH, D-37073 Göttingen, Germany) on a plane $1.5 \mathrm{~mm}$ below the rim of the shell. The manufacturer claim the CMM has a maximum permissible error of $3.2+$ length $/ 150 \mu \mathrm{m}$, in line with ISO $10360-2^{9}$. Radial deformation (displacement) was processed as a function of loading, and a linear best fit was applied to determine the radial stiffness for the tested shells. The radial stiffness was determined for all other shell sizes within that particular wall thickness group by applying a polynomial fit second grade to the results.

Cadaver lab measurements

http://mc.manuscriptcentral.com/(site) 
A cohort of 32 shells were implanted into eight cadavers, the details of which have been published previously ${ }^{7}$, but are summarised in table 1 . Multiple shells were implanted into each acetabulum where the surgeon deemed it suitable. In these instances the surgeon would remove the previous acetabular shell and re-reamed by at least $1 \mathrm{~mm}$ to accommodate the next shell size up.

“[insert Table 1.]"

Deformation was then measured using the ATOS system as described previously ${ }^{5}$. To summarise the method, each shell was measured pre and post implantation and the scans compared to determine the magnitude of the deformation at a plane $1.5 \mathrm{~mm}$ below the rim. The data evaluation method slightly differed to that utilised previously ${ }^{5}$, where the difference in the maximum inscribed circle was compared.

For the current experiments the difference between each data point was utilised. Markers were placed around the rim of the shell to orientate the scans. To improve the ATOS ability to measure reflective surfaces a thin titanium oxide ( $\mathrm{TiO} 2$ ) coating approximately 1 to $2 \mu \mathrm{m}$ thick was applied to the internal surfaces of the shells.

The pre and post implantation scans were placed on top of each other, and displacement was calculated for each individual scanning point. Horizontally the shells rims were matched with by performing a local best fit of the screw holes located at the pole of the shell. Vertical adjustment was performed by matching the planes fitted on top of the shell's rim. The rotational orientation was matched by the aligning the self-adhesive marker points attached to the rim.

Deformation of acetabular shells has previously been shown to be asymmetric ${ }^{3}{ }^{10}$. In order to examine this and how the size of the deformation changes at different points within the shell the deformation data was processed as follows. Firstly the displacement data of the section $1.5 \mathrm{~mm}$ below the rim were normalized to $360^{\circ}$ (see Figure 4). Then the two maximum peaks were determined excluding artefact data caused by soft tissue particles. The mean values calculated from the displacement data, $\pm 1^{\circ}$ either side of the two maximum peaks, were used as maximum peak values. The peak with the higher displacement was further processed as the radial deformation value. The ratio of the two maximum peaks and the angle between them were determined for each deformation scan to investigate the load distribution and load direction mainly causing acetabular shell deformation

For this study positive deformation relates to a decrease in diameter, i.e. deformation towards the centre of the shell. The larger of the two peaks was then used as the maximum radial deformation value. The radial force $(\mathrm{F})$ acting on the shell was then calculated from this maximum radial deformation $\left(\mathrm{U}_{\mathrm{r}}\right)$ and the radial shell stiffness $\left(\mathrm{C}_{\mathrm{r}}\right)$ using the equation of a spring.

$$
F=C_{r} U_{r}
$$

This force was hypothesised to equally act on the bone.

\section{Results}

\section{Cadaver lab measurements}

One shell was excluded from the analysis as the acetabulum had fractured. Therefore 32 shells were included in the analysis. Seventeen of the shells had a $3 \mathrm{~mm}$ wall thickness and 15 shells had a $4 \mathrm{~mm}$ wall thickness. In all cases the surgeon was able to obtain a secure primary fixation suitable for live hip surgery. The median measured radial deformation was $48 \mu \mathrm{m}$ (range 3 to $187 \mu \mathrm{m}$ ) for all shells. 
The median forces (calculated using equation 2) were $246 \mathrm{~N}$ (range $29-784 \mathrm{~N}$ ) for the $3 \mathrm{~mm}$ and 299 $\mathrm{N}$ (range $37-917 \mathrm{~N}$ ) for the $4 \mathrm{~mm}$ wall thicknesses respectively. The median radial shell stiffness was $4192 \mathrm{~N} / \mathrm{mm}$ (range 2920 - $6257 \mathrm{~N} / \mathrm{mm}$ ) for the $3 \mathrm{~mm}$ shell and $9633 \mathrm{~N} / \mathrm{mm}$ (range $6876-14341$ $\mathrm{N} / \mathrm{mm}$ ) for the $4 \mathrm{~mm}$ shell.

A strong correlation was found between the maximum radial deformation and the maximum radial force. However as shown in figure 1 there are two distinct linear relationships, corresponding to the wall thickness. No statistically significant relationship was found between the maximum radial deformation and the radial shell stiffness (figure 2 ) as well as the force, respectively. The mean angle between the maximum deformation peaks was $168.5^{\circ} \pm 13.7^{\circ}$ (figures 3,4 and 5), whilst the ratio of the peaks was 0.75 (range $0.00-0.95$ ) (figure 6).

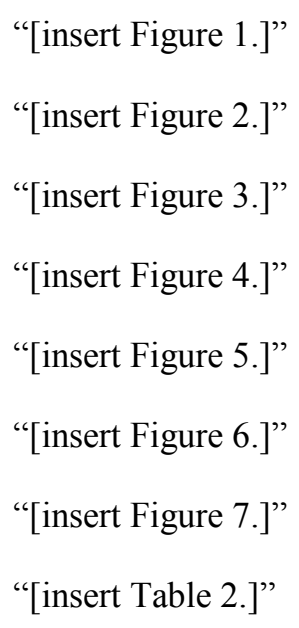

\section{Discussion}

The hypothesis was that the shells with higher stiffness values would have greater resistance to loading and thus have lower deformation values, however this was not proven as no statistically significant correlation was determined between shell stiffness and deformation.

The results also indicated that the deformation is not fully asymmetric (peaks $180^{\circ}$ opposed), but instead there is a median angle discrepancy of $11.5^{\circ}$ between the two maximum positive points of deformation. In addition these maximum points were not equal in size; with the secondary maximum positive peak a median $75 \%$ the size of the primary maximum peak. As the angle between the ischium and ilium is not exactly $180^{\circ}$ this is not unexpected. Numerous studies have previously utilised two-point loading to approximate the deformation of acetabular components 3681112 . Given the relatively small size of the angle discrepancy, the authors suggest two-point loading remains a suitable approximation for simulating acetabular deformation.

Bone et al. have previously published data on the same cohort of cadavers, where deformation was compared to mechanical properties of the bone ${ }^{7}$. The results showed no correlation between either peak modulus and yield stress and the size of the deformation. For the study the authors utilised bone from the femoral head as a surrogate for the acetabulum, potentially explaining the lack of correlation. In the present study bone stiffness and the force exerted by the bone were calculated assuming Hooke's law, with results compared to the size of the deformation. 
There were several limitations to the study. The first was that force exerted on the shell by the bone was not directly measured, but was instead calculated based on the size of the deformation and the shell stiffness using Hooke's law. From that, a combined stiffness was calculated which included a linear-elastic spring model for the bone. Secondly, only six samples were utilised for the shell stiffness measurements with the rest of the values determined using a polynomial function. However, these results had a strong correlation with the calculated values for both the $3 \mathrm{~mm}$ and $4 \mathrm{~mm}$ wall thicknesses $\left(\mathrm{R}^{2}=1\right)$ and $\left(\mathrm{R}^{2}=0.9996\right)$ respectively. The high correlation between the calculated and measured values indicated that this was a suitable method.

During the cadaver experiments the surgeon would insert multiple acetabular shells if the bone stock was of suitable quality. There is a risk of fracturing the acetabulum performing such repeated implantations. Only one acetabulum was found to have fractured. To avoid bias the deformation result was excluded from the analysis.

Radial shell deformation values were calculated to enable a comparison between the individual peaks of deformation to determine if they were the same size. The range of measured radial deformations is comparable to previous studies such as Jin et al. and Liu et al. ${ }^{310}$. The study by Jin et al. reported on a cohort of seven custom made acetabular shells, whilst Liu et al. reported on six Durom acetabular cups. Both studies implanted cobalt chromium acetabular shells into cadavers, whilst the present study implanted generic shells made of TiAl6V4 alloy.

To conclude, the results indicate that the size of the deformation did not correlate to shell stiffness in a statistically significant manner. However as deformation is multifactorial, further work is still required to understand the interplay of variables and how they influence acetabular shell deformation. Such testing should focus on further improving the determination of the material behaviour of the bone together with a theoretically more detailed approach to calculate the resulting forces and the combined stiffness.

\section{Acknowledgements}

The authors would like to thank Milica Manojlovic and Stefan Findeis (Topometric GmbH) and Neal Taylor and Adam Stanley (3D Measurement Company) and Anna Seufert for their work with regard to data acquisition and processing of deformation experiments.

\section{Conflict of interests}

The research was supported by the NIHR Newcastle Biomedical Research Centre. The authors PD, $\mathrm{MF}$ and RP are employed by CeramTec $\mathrm{GmbH}$. Author MCB receives a salary from the joint fund.

\section{References}

1. National Joint Registry N. 2014 National Joint Registry 11th Annual Report [Internet]. Available from:

http://www.njrcentre.org.uk/njrcentre/Reports,PublicationsandMinutes/Annualreports/tabid/86/Defaul t.aspx

2. Meding JB, Small SR, Jones ME, et al. Acetabular cup design influences deformational response in total hip arthroplasty. Clin Orthop Relat Res 2013; 471: 403-409

3. Lin ZM, Meakins S, Morlock MM, et al. Deformation of press-fitted metallic resurfacing cups. Part 1: Experimental simulation. Proc Inst Mech Eng H 2006; 220: 299-309. 
4. Goebel P, Kluess D, Wieding J, et al. The influence of head diameter and wall thickness on deformations of metallic acetabular press-fit cups and UHMWPE liners: a finite element analysis. $\mathrm{J}$ Orthrop Sci 2013; 18: 264-270.

5. Bone MC, Dold P, Flohr M, et al. A novel method for measuring acetabular cup deformation in cadavers. Proc Inst Mech Eng H 2013; 227: 1341-1344

6. Dold P, Bone MC, Flohr M, et al. Validation of an optical system to measure acetabular shell deformation in cadavers. Proc Inst Mech Eng H 2014; 228(8):781-6.

7. Bone MC, Dold P, Flohr M, Preuss R, Joyce TJ, Aspden RM, Holland J, Deehan D. The influence of the strength of bone on the deformation of acetabular shells: A LABORATORY EXPERIMENT IN CADAVERS. Bone \& Joint Journal 2015;97-B(97-B):473-477.

8. Hothan A, Huber G, Weiss C, et al. Deformation characteristics and eigenfrequencies of press-fit acetabular cups. Clin Biomech 2011; 26: 46-51.

9. ISO 10360-2:2009. Geometrical product specifications (GPS) - Acceptance and reverification tests for coordinate measuring machines (CMM) - Part 2: CMMs used for measuring linear dimensions. 10. Liu F, Chen Z, Gu Y, et al. Deformation of the Durom Acetabular Component and Its Impact on Tribology in a Cadaveric Model-A Simulator Study. PLoS ONE 2012; 7: e45786.

11. Squire M, Griffin WL, Mason JB, et al. Acetabular Component Deformation with Press-Fit Fixation. J Arthroplasty 2006; 21: 72-77.

12. Postak PD, Rosca M and Greenwald AS. Do thin acetabular shells increase the disassociation risk of ceramic liners? J Bone Joint Surg Am 2009; 91: 129-133.

Table 1. Details of the cadavers used in the experiments

\begin{tabular}{lllll}
\hline Cadaver no. & Gender & Age & Height $(\mathbf{c m})$ & Weight $\mathbf{( k g )}$ \\
\hline $\mathbf{1}$ & Female & 72 & 170 & 43 \\
$\mathbf{2}$ & Male & 70 & 168 & 73 \\
$\mathbf{3}$ & Male & 80 & 193 & 80 \\
$\mathbf{4}$ & Female & 82 & 152 & 32 \\
$\mathbf{5}$ & Male & 58 & 175 & 113 \\
$\mathbf{6}$ & Male & 85 & 163 & 84 \\
$\mathbf{7}$ & Female & 59 & 163 & 68 \\
$\mathbf{8}$ & Male & 87 & 178 & 86 \\
\hline
\end{tabular}

Table 2. Deformation and stiffness data

\begin{tabular}{c|ccccc} 
Cadaver & $\begin{array}{c}\text { Outer diameter } \\
\text { of the shell } \\
{[\mathbf{m m}]}\end{array}$ & $\begin{array}{c}\text { Wall } \\
\text { thickness } \\
{[\mathbf{m m}]}\end{array}$ & $\begin{array}{c}\text { Radial shell } \\
\text { stiffness } \\
{[\mathbf{N} / \mathbf{m m}]}\end{array}$ & $\begin{array}{c}\text { Max. peak radial } \\
\text { deformation [mm] }\end{array}$ & $\begin{array}{c}\text { Second max. peak } \\
\text { radial deformation } \\
{[\mathbf{m m}]}\end{array}$ \\
\hline $\mathbf{1}$ & 46 & 3 & 5781 & 0,005 & 0,000 \\
$\mathbf{1}$ & 44 & 3 & 6257 & 0,012 & 0,010 \\
$\mathbf{2}$ & 44 & 4 & 14341 & 0,009 & 0,005 \\
$\mathbf{2}$ & 52 & 3 & 4541 & 0,064 & 0,056 \\
$\mathbf{2}$ & 50 & 3 & 4923 & 0,103 & 0,090 \\
$\mathbf{2}$ & 52 & 4 & 10419 & 0,036 & 0,024 \\
& 40 & 4 & 11282 & 0,022 & 0,021
\end{tabular}


2

\begin{tabular}{l|lllll}
$\mathbf{3}$ & 58 & 3 & 3588 & 0,052 & 0,034 \\
$\mathbf{3}$ & 60 & 4 & 7744 & 0,011 & 0,005 \\
$\mathbf{3}$ & 58 & 4 & 8296 & 0,034 & 0,024 \\
$\mathbf{4}$ & 48 & 3 & 5336 & 0,049 & 0,040 \\
$\mathbf{4}$ & 46 & 4 & 12224 & 0,015 & 0,013 \\
$\mathbf{4}$ & 48 & 4 & 12224 & 0,015 & 0,008 \\
$\mathbf{5}$ & 54 & 3 & 4192 & 0,187 & 0,163 \\
$\mathbf{5}$ & 52 & 3 & 4541 & 0,170 & 0,148 \\
$\mathbf{5}$ & 50 & 3 & 4923 & 0,135 & 0,119 \\
$\mathbf{5}$ & 54 & 4 & 9633 & 0,031 & 0,025 \\
$\mathbf{5}$ & 52 & 4 & 10419 & 0,088 & 0,077 \\
$\mathbf{5}$ & 50 & 4 & 11282 & 0,065 & 0,060 \\
$\mathbf{6}$ & 58 & 3 & 3588 & 0,067 & 0,057 \\
$\mathbf{6}$ & 56 & 3 & 3874 & 0,047 & 0,025 \\
$\mathbf{6}$ & 54 & 3 & 4192 & 0,165 & 0,123 \\
$\mathbf{6}$ & 52 & 3 & 4541 & 0,077 & 0,058 \\
$\mathbf{6}$ & 56 & 4 & 8926 & 0,063 & 0,043 \\
$\mathbf{6}$ & 54 & 4 & 9633 & 0,031 & 0,026 \\
$\mathbf{6}$ & 52 & 4 & 10419 & 0,076 & 0,063 \\
$\mathbf{7}$ & 50 & 3 & 4923 & 0,050 & 0,046 \\
$\mathbf{7}$ & 50 & 4 & 11282 & 0,063 & 0,058 \\
$\mathbf{8}$ & 62 & 3 & 3111 & 0,042 & 0,029 \\
$\mathbf{8}$ & 60 & 3 & 3333 & 0,019 & 0,009 \\
$\mathbf{8}$ & 56 & 3 & 3874 & 0,043 & 0,040 \\
$\mathbf{8}$ & 58 & 4 & 8296 & 0,018 & 0,014 \\
& & & & &
\end{tabular}




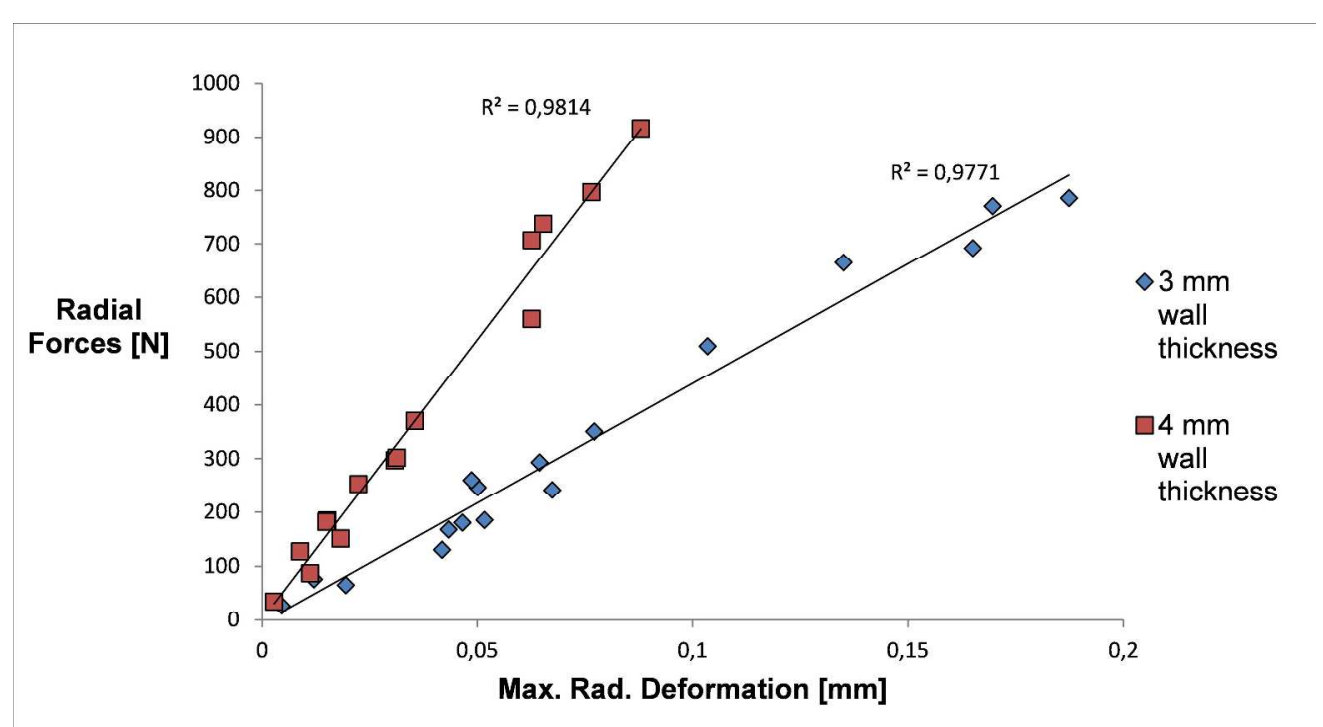

Figure 1. Graph of measured radial deformation against measured radial force $1197 \times 649 \mathrm{~mm}(96 \times 96 \mathrm{DPI})$ 
Figure 2. Graph of radial shell stiffness plotted against radial deformation $950 \times 566 \mathrm{~mm}(96 \times 96 \mathrm{DPI})$ 

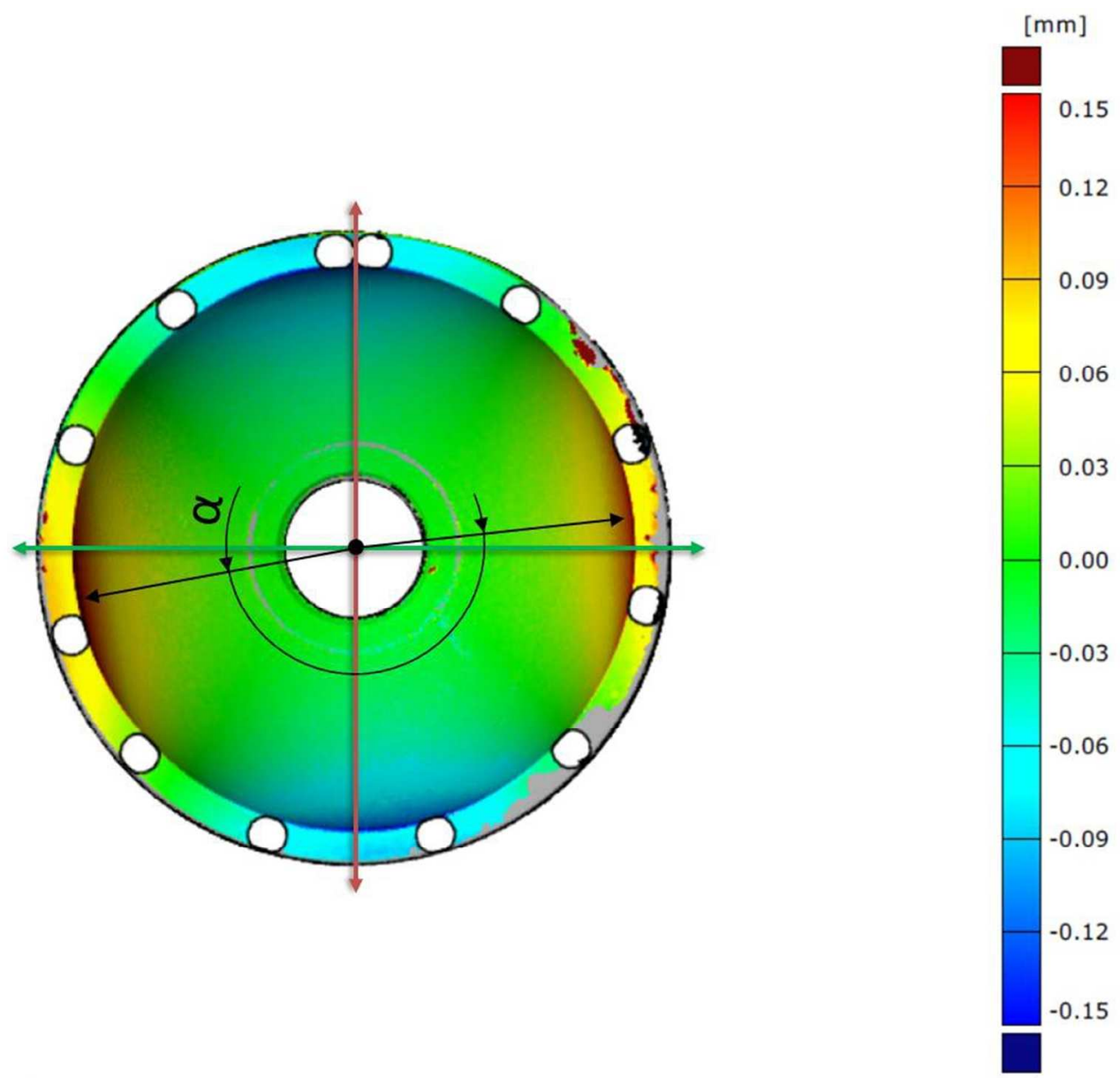

Figure 3. A "heat map" of a deformed shell. Red indicates a reduction in the shell diameter, whilst blue indicates an increase in the shell diameter. The red regions indicate the maximum positive deformation with (a) denoting the angle between the centres of these regions $171 \times 161 \mathrm{~mm}(150 \times 150 \mathrm{DPI})$ 


\section{Page 11 of 14}

2

3

4

5

6

7

8

9

10

11

12

13

14

15

16

17

18

19

20

21

22

23

24

25

26

27

28

29

30

31

32

33

34

35

36

37

38

39

40

41

42

43

44

45

46

47

48

49

50

51

52

53

54

55

56

57

58

59

60

Figure 4. Deformation data plotted against angle. a correlates to the angle between the maximum peaks, whilst $\Delta$ represents the difference in size between the maximum peaks

$127 \times 82 \mathrm{~mm}(150 \times 150 \mathrm{DPI})$ 
Figure 5. Graph showing the angle between the maximum positive deformation peaks plotted against radial deformation $1026 \times 616 \mathrm{~mm}(96 \times 96 \mathrm{DPI})$ 
Figure 6. Force ratio of the maximum positive deformation peaks plotted against radial deformation. A logarithmic trend line and $\mathrm{R}^{2}$ value have been added to the graph $1027 \times 592 \mathrm{~mm}(96 \times 96 \mathrm{DPI})$ 
Figure 7. Graph showing combined stiffness of bone surrogate and shell plotted against radial deformation $998 \times 592 \mathrm{~mm}(96 \times 96$ DPI $)$ 